\title{
Catalytic Ring Opening of Perhydroindan - Hydrogenolytic and Cationic Reaction Paths
}

\author{
Giuseppe BELLUSSI ${ }^{1}$, Andreas HAAS ${ }^{2}$, Sandra RABL ${ }^{2}$, Dominic SANTI $^{2}$, Marco FERRARI ${ }^{1}$, \\ Vincenzo CALEMMA ${ }^{1}$, Jens WEITKAMP ${ }^{2, *}$ \\ ${ }^{1}$ Eni S.p.A., R\&M Division, Via F. Maritano 26, 20097 San Donato Milanese, Italy \\ ${ }^{2}$ Institute of Chemical Technology, University of Stuttgart, 70550 Stuttgart, Germany
}

\begin{abstract}
Perhydroindan (bicyclo[4.3.0]nonane) was converted in a flow-type apparatus under a hydrogen pressure of $5 \mathrm{MPa}$ on six different catalysts, namely on a bifunctional $\mathrm{Pd} / \mathrm{Na}, \mathrm{H}-\mathrm{B}$ eta zeolite, on $\mathrm{Ir} / \mathrm{Na}, \mathrm{H}-\mathrm{Y}$ and $\mathrm{Pt} / \mathrm{Na}, \mathrm{H}-\mathrm{Y}$ zeolites with a low concentration of Brønsted acid sites, and on three catalysts containing the three noble metals on the non-acidic support silica. On the bifunctional zeolite $\mathrm{Pd} / \mathrm{Na}, \mathrm{H}-\mathrm{Beta}$, skeletal isomerization of perhydroindan was the primary reaction followed by opening of one naphthenic ring, the formation of open-chain nonanes in low yields of ca. $6 \%$, and hydrocracked products $\mathrm{C}_{8}$ - The carbon number distribution of the latter was volcano-shaped with no $\mathrm{C}_{1}, \mathrm{C}_{2}, \mathrm{C}_{7}$, and $\mathrm{C}_{8}$ indicating a carbocationic hydrocracking of $\mathrm{C}_{9}$ precursors with one naphthenic ring. On Ir/Na, $\mathrm{H}-\mathrm{Y}$ and $\mathrm{Pt} / \mathrm{Na}, \mathrm{H}-\mathrm{Y}$ ("high-performance ring-opening catalysts"), ring opening and hydrocracking to $\mathrm{C}_{8^{-}}$occurred by hydrogenolysis on the respective metal. Opening of the five-membered ring was found to be much faster than opening of the six-membered ring, in agreement with literature reports. The maximal selectivities of open-chain nonanes (OCNs) attained on $\mathrm{Ir} / \mathrm{Na}, \mathrm{H}-\mathrm{Y}$ and $\mathrm{Pt} / \mathrm{Na}, \mathrm{H}-\mathrm{Y}$ were very high, viz. 49\% and 54\%, respectively, and significantly better than those of the open-chain decanes observed previously with decalin as model hydrocarbon. The OCNs formed on $\mathrm{Pt} / \mathrm{Na}, \mathrm{H}-\mathrm{Y}$ were much less branched than those formed on $\mathrm{Ir} / \mathrm{Na}, \mathrm{H}-\mathrm{Y}$ which was interpreted in terms of the different hydrogenolysis mechanisms on both metals. Valuable ancillary mechanistic information was obtained from the selectivities of perhydroindan hydroconversion on the three noble metals on silica. In contrast to Pd/silica, Ir/silica and Pt/silica gave appreciable selectivities of OCNs as well, yet the maximum values of these selectivities were lower than those obtained on the two high-performance zeolite catalysts.
\end{abstract}

Key words: ring opening; hydrogenolysis; bifunctional catalysis; perhydroindan; open-chain nonanes; noble metals; silica; zeolites CLC number: O643 Document code: A

Received 3 August 2011. Accepted 21 September 2011.

*Corresponding author. Tel.: +49-711-685 64060; Fax: +49-711-685 64065; E-mail: jens.weitkamp@itc.uni-stuttgart.de English edition available online at Elsevier ScienceDirect (http://www.sciencedirect.com/science/journal/18722067).

Contributing to the manufacture of high-quality, environmentally benign transportation fuel is among the important tasks of modern catalysis. Today's diesel fuels, for example, have to meet a variety of rather stringent specifications which pertain, inter alia, to the ignition characteristics in the engine, the cold-flow properties, the propensity of forming soot and particulate matter, and the amount and composition of the exhaust gas. Moreover, with the ongoing trend of using diesel engines in passenger cars, the consumption of high-quality diesel fuel has been steadily increasing in many regions of the world. In this context, upgrading of low-quality refinery streams in the boiling range of diesel, such as light cycle oils from fluid catalytic crackers or middle distillates from delayed or fluid cokers, into hydrogen-rich blending components for diesel fuels is of ever increasing attractiveness.

Polynuclear aromatic hydrocarbons (PAHs) are particularly undesired constituents of diesel fuels. They have very low cetane numbers (CNs) [1,2] and poor cold-flow proper- ties, and they are generally considered to be precursors of particulate matter. Moreover, due to their very low hydrogen content, they give rise to relatively high emissions of carbon dioxide. Probably the best solution of the PAH problem is their selective catalytic conversion into hydrogen-rich hydrocarbons under retention of the carbon number. An ideal upgrading of PAH-rich diesel fractions would entail a complete catalytic hydrogenation of the aromatic ring system to multi-ring naphthenes followed by their ring opening (or, synonymously, hydrodecyclization) into naphthenes with a lower number of rings and, eventually, alkanes with the same carbon number. A closer examination of the attainable improvement of the cetane numbers and cold-flow properties indicates that particularly desirable products are mildly branched iso-alkanes with one or two branchings and alkylnaphthenes with a single ring $[1,2]$.

Since about 2000 , the chemistry of catalytic ring opening was intensely studied using model hydrocarbons. In the majority of cases, naphthalene or its hydrogenated forms 
tetralin or decalin were used as reactants arguing that the partial or complete hydrogenation of PAHs can be considered as state-of-the-art catalysis. The ring opening catalysts employed in these studies can be broadly classified into (i) monofunctional acidic zeolites, mostly faujasites, Beta or mordenite $[3,4]$; (ii) bifunctional versions of the same zeolites with a high concentration of acid sites or ordered mesoporous materials loaded with a noble metal [4-15], and (iii) noble metals on non-acidic supports [16]. The performance of monofunctional acidic zeolites in ring opening was generally found to be poor with maximal yields of the desired products below ca. $20 \%$ and deactivation due to the formation of carbonaceous deposits. Bifunctional catalysts appear to be more promising, since they usually do not deactivate, and higher yields of ring-opening products are attainable. Only scant literature is available on hydrogenolytic ring opening over noble metals, but in one very thorough study [16] many details of ring cleavage by hydrogenolysis were discussed.

Until recently, there was much uncertainty concerning the precise nature of the ring-opening products that can be made on the various catalysts. Ring opening of decalin or tetralin was generally reported to give $\mathrm{C}_{10}$ naphthenes with one remaining ring, whereas the very desirable open-chain decanes (OCDs) were not addressed at all. In just one report quantitative information concerning their formation was given: Mouli et al. [15] reported that decalin hydroconversion on a Pt,Ir/H-Y zeolite gave OCDs in maximal selectivities and yields of $5 \%$ and $4 \%$, respectively. Using improved analytical procedures we found that OCDs are made from decalin on typical bifunctional catalysts in maximal yields of ca. $10 \%$ to $15 \%$ [17-19]. More recently, we introduced a new class of iridium- or platinum-containing zeolite catalysts with a metal content of ca. $3 \mathrm{wt} \%$ and a low concentration of Brønsted acid sites which enable much higher yields of open-chain decanes close to $40 \%$ in ring opening of decalin [20]. We refer to these zeolites as "high-performance ring-opening catalysts" (HIPEROCs).

In this paper, we report on ring-opening studies carried out with the model hydrocarbon perhydroindan (bicyclo[4.3.0]nonane). These data supplement those gained previously with decalin as reactant [17-20] because perhydroindan (PHI) contains both a six-membered and a five-membered naphthenic ring. Three types of catalysts were used in the present study, viz. a typical bifunctional zeolite ( $\mathrm{Pd} / \mathrm{Na}, \mathrm{H}-\mathrm{Beta})$, two high-performance zeolites ( $\mathrm{Ir} / \mathrm{Na}, \mathrm{H}-\mathrm{Y}$ and $\mathrm{Pt} / \mathrm{Na}, \mathrm{H}-\mathrm{Y}$ ), and the three noble metals on a non-acidic support (Ir/silica, Pt/silica, and Pd/silica).

It is known from the literature that in the hydrogenolysis of perhydroindan, e.g., on $\mathrm{Ni} /$ kieselguhr [21], $\mathrm{Ni} / \mathrm{Al}_{2} \mathrm{O}_{3}$ [22], or $\mathrm{Ir} / \mathrm{Al}_{2} \mathrm{O}_{3}[16,23]$, the five-membered naphthenic ring is preferentially cleaved, thereby leading to $\mathrm{C}_{9}$ one-ring naphthenes with a remaining six-membered ring. The hydrogenolysis of indan, in which the six-membered ring is aromatic, shows a comparable selectivity on $\mathrm{Ni} / \mathrm{Al}_{2} \mathrm{O}_{3}$ [24] and $\mathrm{Pt} /$ boehmite and Ir,Pt/boehmite [25] leading mainly to 2-ethyltoluene beside significantly less propylbenzene, i.e., the bond between two secondary carbon atoms in the five-membered ring is preferentially cleaved.

\section{Experimental}

\subsection{Preparation of the catalysts}

Ring opening of perhydroindan was studied on six catalysts covering a broad range of acidities of the supports and using three different noble metals, viz. iridium, platinum, and palladium. Two catalysts were based on zeolite $\mathrm{Y}$ and one on zeolite Beta, and the three noble metals used were also supported on silica as a non-acidic carrier.

Zeolite Na-Y $\left(n_{\mathrm{Si}} / n_{\mathrm{Al}}=2.41\right)$ was purchased from Strem Chemicals, Inc. Iridium or platinum were loaded onto the zeolite in its sodium form by ion exchange with $\left[\operatorname{Ir}\left(\mathrm{NH}_{3}\right)_{5} \mathrm{Cl}\right] \mathrm{Cl}_{2}$ or $\left[\mathrm{Pt}\left(\mathrm{NH}_{3}\right)_{4}\right] \mathrm{Cl}_{2}$, respectively. For the preparation of $2.9 \mathrm{Ir} / \mathrm{Na}_{0.90}, \mathrm{H}_{0.10}-\mathrm{Y}$ and $3.7 \mathrm{Pt} / \mathrm{Na}_{0.86}, \mathrm{H}_{0.14}-\mathrm{Y}$ (the initial numbers stand for the metal content in $\mathrm{wt} \%$ on the dry catalysts, and the subscripts indicate the molar ratio of the respective cation to aluminum), $280 \mathrm{mg}$ of the iridium complex or $291 \mathrm{mg}$ of the platinum complex were dissolved in $50 \mathrm{ml}$ of demineralized water, and the solution was added dropwise to a suspension of $4.0 \mathrm{~g}$ (on a dry basis) of Na-Y in $150 \mathrm{ml}$ of demineralized water at room temperature under vigorous stirring. When the solution of the complex had completely been added, the zeolite suspension was heated to $80{ }^{\circ} \mathrm{C}$ and stirred for $4 \mathrm{~h}$ at this temperature. Thereafter, the suspension was again cooled to room temperature and, in case of an ion exchange with the iridium complex, stirred for another $19 \mathrm{~h}$. Subsequently, the zeolite was filtered off, washed with demineralized water, and dried at $80^{\circ} \mathrm{C}$. Next, the complex was decomposed by heating the zeolite in an oven under an air flow at $300{ }^{\circ} \mathrm{C}$ for $2 \mathrm{~h}$. After cooling, the catalyst powder was pressed into tablets without a binder at a pressure of $127 \mathrm{MPa}$, and the resulting tablets were crushed. The particle size fraction from 0.20 to $0.32 \mathrm{~mm}$ was filled into the fixed-bed reactor.

Zeolite Beta was synthesized via the dry-gel conversion method [26,27]: $6.65 \mathrm{~g}$ aluminum sulfate 18 hydrate (Riedel-de Haën, grade chemically pure) were dissolved in $5.0 \mathrm{~g}$ demineralized water, and the solution was heated to $80{ }^{\circ} \mathrm{C}$ for $30 \mathrm{~min}$ under stirring. Meanwhile, $49.14 \mathrm{~g}$ colloidal silica (Aldrich, Ludox HS40, $40 \mathrm{wt} \% \mathrm{SiO}_{2}$ ), $50.92 \mathrm{~g}$ aqueous tetraethylammonium hydroxide solution (SigmaAldrich, $35 \mathrm{wt} \%$ ), and $8.62 \mathrm{~g} \mathrm{NaOH}$ solution (4 mol/L) were mixed and stirred for $30 \mathrm{~min}$ at room temperature. 
Subsequently, the two solutions were combined and stirred for another $2 \mathrm{~h}$ at room temperature. The resulting gel was heated to $80^{\circ} \mathrm{C}$ and dried while stirring. The dry-gel conversion was carried out in several Teflon-lined autoclaves, each of which had been filled with ca. $1.5 \mathrm{~g}$ of the dried gel at the top and $2 \mathrm{~g}$ of demineralized water at the bottom, at $175^{\circ} \mathrm{C}$ for $48 \mathrm{~h}$. The resulting zeolite was dried for at least $12 \mathrm{~h}$ at $80^{\circ} \mathrm{C}$ in an oven.

The template was removed from zeolite Beta by first heating in a nitrogen flow of $58 \mathrm{~L} / \mathrm{h}$ from room temperature to $450{ }^{\circ} \mathrm{C}$ with a rate of $1{ }^{\circ} \mathrm{C} / \mathrm{min}$, holding at $450{ }^{\circ} \mathrm{C}$ for $24 \mathrm{~h}$, then switching to a flow of synthetic air with a rate of $58 \mathrm{~L} / \mathrm{h}$, and holding the temperature and air flow for another $24 \mathrm{~h}$. To generate the sodium form, the zeolite was stirred two times for $4 \mathrm{~h}$ at $80^{\circ} \mathrm{C}$ in $40 \mathrm{ml}$ of a 1 molar aqueous solution of $\mathrm{NaNO}_{3}$ per $1 \mathrm{~g}$ of dry zeolite. After each ion exchange the samples were filtered and washed with demineralized water until the washing water was nitrate-free. For the detection of nitrate ions test sticks with a lower detection limit of $10 \mathrm{mg} / \mathrm{L}$ were used. They were then dried at $80{ }^{\circ} \mathrm{C}$ in an air oven for at least $12 \mathrm{~h}$. The calculated $n_{\mathrm{Si}} / n_{\mathrm{Al}}$ ratio of the dry gel was 13.8 , and the $n_{\mathrm{Si}} / n_{\mathrm{Al}}$ ratio of the final zeolite amounted to 14.0 , as determined by optical emission spectrometry with inductively coupled plasma (ICP-OES, Varian Vista-MPX CCD).

Palladium was introduced into zeolite Na-Beta by ion exchange with $\left[\mathrm{Pd}\left(\mathrm{NH}_{3}\right)_{4}\right] \mathrm{Cl}_{2}: 49.3 \mathrm{mg}$ of the complex were dissolved in $50 \mathrm{ml}$ of demineralized water, and the solution was added dropwise to a suspension of $2.0 \mathrm{~g}$ (on a dry basis) of Na-Beta in $200 \mathrm{ml}$ of demineralized water under vigorous stirring. Afterwards, the suspension was heated to $80{ }^{\circ} \mathrm{C}$ and stirred for $24 \mathrm{~h}$ at this temperature. The zeolite powder was then filtered off, washed with demineralized water, dried at $80^{\circ} \mathrm{C}$, and transformed into particles with a size from 0.20 to $0.32 \mathrm{~mm}$ as described above for the Y-type zeolites. This catalyst showed a typical bifunctional behavior in the decalin hydroconversion, very similar to iridium- or platinum-containing La-X zeolites [17] with an "M-shaped" carbon number distribution of the hydrocracked products, when prepared without an oxidation step. Hence, no oxidative treatment was applied to the palladium-loaded zeolite Beta for the experiments with perhydroindan either.

Silica (Aerosil 380, Evonik Degussa $\mathrm{GmbH}$ ) was loaded with $\left[\operatorname{Ir}\left(\mathrm{NH}_{3}\right)_{5} \mathrm{Cl}\right] \mathrm{Cl}_{2},\left[\mathrm{Pt}\left(\mathrm{NH}_{3}\right)_{4}\right] \mathrm{Cl}_{2}$, or $\left[\mathrm{Pd}\left(\mathrm{NH}_{3}\right)_{4}\right] \mathrm{Cl}_{2}$ via electrostatic adsorption [28]: $8.0 \mathrm{~g}$ of silica were suspended in $100 \mathrm{ml}$ of demineralized water, and this suspension was vigorously stirred for $2 \mathrm{~h}$ while the $\mathrm{pH}$ was adjusted to 10 by dropwise addition of a 1 molar aqueous solution of ammonia. Subsequently, $206 \mathrm{mg}$ of the iridium complex, $145 \mathrm{mg}$ of the platinum complex, or $112 \mathrm{mg}$ of the palladium complex dissolved in $30 \mathrm{ml}$ of demineralized water were added dropwise under ongoing stirring. Subsequently, stirring was continued for another $18 \mathrm{~h}$, next the solid was filtered off, washed with demineralized water, and dried at $80^{\circ} \mathrm{C}$. The catalyst powder was then transformed into particles with a size between 0.20 and $0.32 \mathrm{~mm}$ as described above for the catalysts based on zeolite Y. These particles were transferred into the catalytic reactor where they were treated in an air stream at $0.1 \mathrm{MPa}$ and $150{ }^{\circ} \mathrm{C}$ for $3 \mathrm{~h}$.

On all six catalysts, the respective noble metal was reduced inside the catalytic reactor in a flow of hydrogen at $0.1 \mathrm{MPa}$ and $400{ }^{\circ} \mathrm{C}$ for $2 \mathrm{~h}$.

\subsection{Characterization of the catalysts}

For elemental analysis of $\mathrm{Si}, \mathrm{Al}, \mathrm{Na}, \mathrm{Ir}, \mathrm{Pt}$, and $\mathrm{Pd}$, ICP-OES was used. The catalysts were dissolved in a mixture of diluted hydrofluoric acid and aqua regia. Throughout this paper, the metal loading is defined as the mass of metal per mass of the water-free catalyst. Details concerning the determination of the latter may be found in Ref. [17].

The porosity of the catalyst supports was measured by nitrogen physisorption at $T=-196^{\circ} \mathrm{C}$ in a Quantachrome Autosorb-1-C instrument. For evaluating the BET specific surface area the range of $p / p_{0}$ between 0.1 and 0.3 was used. A cross-sectional area of $1.62 \mathrm{~nm}^{2}$ was assumed for the $\mathrm{N}_{2}$ molecule. The dispersion of the noble metal was determined by measuring the amount of irreversibly adsorbed hydrogen in the same Quantachrome Autosorb-1-C instrument at $T=$ $40{ }^{\circ} \mathrm{C}$. Adsorption isotherms were recorded in a pressure range of 11 to $107 \mathrm{kPa}$ for the iridium and platinum catalysts. To exclude the formation of a $\beta$-hydride phase on palladium, adsorption isotherms for both palladium catalysts were measured at lower pressures in the range of 0.3 to $2.7 \mathrm{kPa}$ [29]. An adsorption stoichiometry of $n_{\mathrm{H}} / n_{\text {metal }}=1$ was assumed. For details of the experimental procedures of chemi- and physisorption see Ref. [17].

FT-IR spectroscopy with pyridine as a probe molecule was used to collect information on the concentration and strength of the Brønsted acid sites of the catalysts. A Bruker Vector 22 spectrometer equipped with a high-vacuum sample cell was employed. Self-supporting wafers were made from the powdered catalysts. In case of the two Y-type catalysts the metal complexes were decomposed in an air stream at $300{ }^{\circ} \mathrm{C}$ prior to the wafer preparation. Wafers of the palladium-loaded zeolite Beta and of the silica-supported catalysts were made from the precursor after drying at $80^{\circ} \mathrm{C}$. Subsequently, the silica catalysts were treated in an air flow in the sample holder of the IR cell at $150{ }^{\circ} \mathrm{C}$. On all six catalysts, after reduction of the noble metal with hydrogen at $T=500{ }^{\circ} \mathrm{C}$, pyridine was adsorbed at $100{ }^{\circ} \mathrm{C}$, and desorption took place between $T=250$ and $500{ }^{\circ} \mathrm{C}$ in steps of $50{ }^{\circ} \mathrm{C}$. For the quantitative evaluation, the band at $1545 \mathrm{~cm}^{-1}$ was integrated. For experimental details 
and the evaluation of the IR measurements see Ref. [20].

\subsection{Hydroconversion of perhydroindan and product analysis}

Perhydroindan (bicyclo[4.3.0]nonane) was prepared by hydrogenation of indan (Aldrich) in a high-pressure flow-type apparatus on a $1.0 \mathrm{Pt} / \gamma$-alumina catalyst. During this hydrogenation the total pressure, temperature, $W H S V$, and $n_{\mathrm{H}_{2}} / n_{\text {indan }}$ ratio amounted to $8.1 \mathrm{MPa}, 200^{\circ} \mathrm{C}, 0.5 \mathrm{~h}^{-1}$, and 20 , respectively. The purity of the resulting perhydroindan was $96.7 \mathrm{wt} \% \quad(67.4 \mathrm{wt} \% \quad$ cis-isomer, $29.3 \mathrm{wt} \%$ trans-isomer, impurities: $0.7 \mathrm{wt} \% \mathrm{C}_{7}, \mathrm{C}_{8}$, and $\mathrm{C}_{9}$ hydrocarbons; $2.6 \mathrm{wt} \% \mathrm{C}_{10}$ and $\mathrm{C}_{11}$ hydrocarbons). For the hydroconversion of perhydroindan on the six catalysts described in Section 1.1 a second high-pressure flow-type apparatus was used. Its main parts were a saturator filled with an inert solid (Merck, Chromosorb P/AW, particle size 0.25 to $0.60 \mathrm{~mm}$ ) in which the desired gaseous $\mathrm{H}_{2} /$ perhydroindan streams were generated, a fixed-bed reactor accommodating the solid catalyst, and a heated gas sampling valve which, upon depressurization of the product stream in a needle valve, allowed the on-line introduction of full product samples into a capillary gas chromatograph (Hewlett-Packard HP 6890N) equipped with a Supelco Petrocol DH 150 $(150 \mathrm{~m} \times 0.25 \mathrm{~mm} \times 1.0 \mu \mathrm{m})$ capillary column and a flame ionization detector. The gas stream leaving the sampling valve was routed through a cooling trap held at $-10{ }^{\circ} \mathrm{C}$ where an integral liquid sample of the product hydrocarbons was collected for several hours. The mass of dry catalyst, the total pressure, the partial pressure of perhydroindan at the reactor entrance, and the $L H S V$ amounted to 0.17 to $0.24 \mathrm{~g}, 5.0$ to $5.2 \mathrm{MPa}, 17$ to $18 \mathrm{kPa}$, and 0.4 to $0.5 \mathrm{~h}^{-1}$, respectively. The reaction temperature was varied from 210 to $430{ }^{\circ} \mathrm{C}$.

The entire quantitative evaluation of the catalytic experiments was based on the on-line analyses of the full product samples. Typically, the first of these samples was taken after a time-on-stream of $4 \mathrm{~h}$. The integral liquid product samples collected in the cooling trap were used for qualitative peak assignment via ancillary off-line GC-MS analyses. A second gas chromatograph (Agilent 6890N) which was also equipped with a Supelco Petrocol DH 150 capillary column and coupled to a mass spectrometer (Agilent 5876B inert XL MSD) was used for this purpose. Peak assignment was further refined by co-injection of (i) pure hydrocarbons, whenever these were commercially available, and (ii) a mixture of nonane isomers of known composition which was generated by isomerization of $n$-nonane on a bifunctional $0.52 \mathrm{Pd} / \mathrm{Na}_{0.69}, \mathrm{H}_{0.31}-\mathrm{Y}$ zeolite catalyst. This method for peak assignment has previously proven to be very efficient for the identification of the even more complex hydrocarbon mixtures made by ring opening of decalin [17].

The two stereoisomeric reactants cis- and trans-perhydroindan were lumped to a single pseudo-reactant perhydroindan. The numerous individual product hydrocarbons will be classified into the following groups:

(1) sk-Isos: Skeletal isomers of perhydroindan with two remaining naphthenic rings, a molar mass $M=124 \mathrm{~g} / \mathrm{mol}$, and a molecular formula $\mathrm{C}_{9} \mathrm{H}_{16}$;

(2) ROPs: Ring-opening products with one remaining naphthenic ring, $M=126 \mathrm{~g} / \mathrm{mol}, \mathrm{C}_{9} \mathrm{H}_{18}$; and the corresponding aromatics, $M=120 \mathrm{~g} / \mathrm{mol}, \mathrm{C}_{9} \mathrm{H}_{12}$;

(3) OCNs: Open-chain nonanes, $M=128 \mathrm{~g} / \mathrm{mol}, \mathrm{C}_{9} \mathrm{H}_{20}$;

(4) DHPs: Dehydrogenated products, namely indan and traces of indene;

(5) $\mathrm{C}_{8^{-}}$: Hydrocracked products with less than nine carbon atoms.

Hydrocarbons with more than nine carbon atoms and seemingly decreasing selectivities of $\mathrm{C}_{8}$ - hydrocarbons with increasing temperature at low conversions are impurities in the reactant and not formed by catalytic conversion. Hence, selectivities and yields of products are calculated without incorporating these hydrocarbons.

For the quantitative discussion of the hydrocracking reactions to $\mathrm{C}_{8}$ - hydrocarbons, the modified hydrocracking selectivity $S_{\mathrm{j}}^{*}$ will be used. It is defined as the molar amount of an individual hydrocarbon or a group of hydrocarbons $j$ formed divided by the molar amount of perhydroindan converted into $\mathrm{C}_{8^{-}}$products. For more details concerning the calculation of $S_{\mathrm{j}}{ }^{*}$, the perhydroindan conversion $X_{\mathrm{PHI}}$, the yields of products $Y_{\mathrm{j}}$, and the selectivities of products $S_{\mathrm{j}}$ see Ref. [17], in which the procedures of calculating these quantities are given for the hydroconversion of decalin.

\section{Results and discussion}

\subsection{Characterization of the catalysts}

In Table 1 physico-chemical characteristics of the three catalyst supports and the six metal-containing catalysts are presented. During the ion exchange of the zeolites with the noble-metal salts, part of the sodium cations is replaced by the respective metal complex cation. In the subsequent oxidation and/or reduction of the noble-metal cations, protons are formed. These protons cannot be determined by ICP-OES, hence the difference between the molar amount of aluminum and sodium is attributed to protons as charge-compensating cations. In zeolite Beta with its higher $n_{\mathrm{Si}} / n_{\mathrm{Al}}$ ratio, the total amount of charge-compensating cations is much smaller, thus a correspondingly higher molar fraction of sodium is replaced by the palladium complex. The metal dispersion decreases in the order $\mathrm{Ir}>\mathrm{Pt}>\mathrm{Pd}$, in 
Table 1 Physico-chemical properties of the supports and the catalysts

\begin{tabular}{lcccccc}
\hline Sample & $n_{\mathrm{Si}} / n_{\mathrm{Al}}$ & $n_{\mathrm{Na}} / n_{\mathrm{Al}}$ & $\begin{array}{c}A_{\mathrm{BET}} / \\
\left(\mathrm{m}^{2} / \mathrm{g}\right)\end{array}$ & $\begin{array}{c}V_{\mathrm{p}} / \\
\left(\mathrm{cm}^{3} / \mathrm{g}\right)\end{array}$ & $\begin{array}{c}\text { Metal load- } \\
\text { ing (wt\%) }\end{array}$ & $\begin{array}{c}\text { Metal } \\
\text { dispersion }\end{array}$ \\
\hline Na-Y & 2.41 & 0.96 & 885 & 0.63 & n.a. & n.a. \\
Na-Beta & 14.0 & 0.93 & 752 & 0.58 & n.a. & n.a. \\
Silica & n.a. & n.a. & 385 & 1.07 & n.a. & n.a. \\
Ir/Na,H-Y & 2.41 & 0.90 & 921 & 0.55 & 2.9 & 1.13 \\
$\mathrm{Pt} / \mathrm{Na}, \mathrm{H}-\mathrm{Y}$ & 2.41 & 0.88 & 559 & 0.35 & 3.7 & 0.62 \\
$\mathrm{Pd} / \mathrm{Na}, \mathrm{H}-\mathrm{Beta}$ & 14.0 & 0.70 & 791 & 0.72 & 1.1 & 0.04 \\
$\mathrm{Ir} /$ silica & n.a. & n.a. & 281 & 0.99 & 0.77 & 1.52 \\
$\mathrm{Pt} /$ silica & n.a. & n.a. & 295 & 0.74 & 0.93 & 0.99 \\
$\mathrm{Pd} /$ silica & n.a. & n.a. & 352 & 1.18 & 0.60 & 0.14 \\
\hline
\end{tabular}

$A_{\mathrm{BET}}$ : specific BET surface area; $V_{\mathrm{p}}$ : pore volume; n.a.: not applicable.

qualitative accordance with literature data [30,31]. The values for the iridium dispersion above unity could have their origin in a real adsorption stoichiometry higher than the anticipated one, i.e. $n_{\mathrm{H}} / n_{\mathrm{Ir}}>1$ [30]. Perhaps, the very low dispersion of 0.04 for Pd supported on zeolite Beta stems from a reduction without a prior oxidation treatment.

The concentrations of Brønsted acid sites on the two faujasites and their decline with increasing temperature (Table 2) largely agree with those published recently for similar catalysts used for ring opening of the model hydrocarbon cis-decalin $[17,20]$. The relatively low concentration of Brønsted acid sites on zeolite $\mathrm{Pd} / \mathrm{Na}, \mathrm{H}$-Beta compared to the faujasites measured at low desorption temperatures is attributed to the lower metal content. Note, however, that the relative decrease of the concentration of Brønsted acid sites with temperature, which is a semiquantitative measure of the acid strength, is much more pronounced for the Y-type catalysts indicating that the Brønsted acid sites on zeolite Beta are stronger. No pyridine adsorption occurred on the metal-loaded silica catalysts, so Brønsted acid sites appear to be absent rendering these catalysts particularly suitable for studying the catalytic action of the pure metal functions.

Table 2 Concentration of Brønsted acid sites of the metal-containing zeolite catalysts as determined by FT-IR spectroscopy with pyridine as probe at different desorption temperatures $\left(T_{\text {Des }}\right)$

\begin{tabular}{|c|c|c|c|c|c|c|c|}
\hline \multirow{2}{*}{ Catalyst } & \multirow[b]{2}{*}{$T_{\text {Des }} /{ }^{\circ} \mathrm{C}:$} & \multicolumn{6}{|c|}{$\left(n_{\text {pyridine }} / m_{\text {catalyst }}\right) /(\mu \mathrm{mol} / \mathrm{g})$} \\
\hline & & 250 & 300 & 350 & 400 & 450 & 500 \\
\hline $\mathrm{Ir} / \mathrm{Na}, \mathrm{H}-\mathrm{Y}$ & & 203 & 170 & 97 & 68 & 44 & 12 \\
\hline $\mathrm{Pt} / \mathrm{Na}, \mathrm{H}-\mathrm{Y}$ & & 216 & 176 & 124 & 81 & 36 & 2 \\
\hline $\mathrm{Pd} / \mathrm{Na}, \mathrm{H}-\mathrm{Bet}$ & & 111 & 106 & 99 & 80 & 56 & 26 \\
\hline
\end{tabular}

\subsection{Stereoisomerization of cis- and trans-perhydroindan}

A mixture of both stereoisomers consisting of $70 \%$ cisand 30\% trans-perhydroindan was used as feed in all catalytic experiments. In the products of the catalytic hydro- conversion the mole fraction of cis-perhydroindan assumed values between $47 \%$ and $61 \%$, regardless of the catalyst used and the perhydroindan conversion attained in a very broad range from a few percent to ca. $90 \%$. Moreover, these values compare well with the results of Frye and Weitkamp [32] and of Allinger and Coke [33] who converted indene or perhydroindan, respectively, on $\mathrm{Pd} /$ carbon catalysts and found mole fractions of cis-perhydroindan ranging from $53 \%$ to $57 \%$ and $50 \%$ to $58 \%$, respectively. It appears to us that equilibrium is rapidly established between the two stereoisomers, in analogy to the very rapid equilibration of cis- and trans-decalin observed in a recent study with bifunctional $\mathrm{Ir} /-$ and $\mathrm{Pt} / \mathrm{La}-\mathrm{X}$ zeolite catalysts [17]. For the equilibration of the stereoisomers, mechanisms at the Brønsted acid sites via carbocations or at the noble-metal sites via olefins can be invoked [34]. From the fact that the cis/trans-stereoisomerization occurs as the fastest reaction on all six catalysts used in this study, including the three non-acidic noble-metal/silica catalysts, we conclude that, under our conditions, the stereoisomerization proceeds on the noble metals. This is in agreement with a finding reported by Lai and Song [35] that decalin stereoisomerization proceeds readily on metal-containing H-mordenites, but much more slowly on metal-free H-mordenite.

In view of the rapid stereoisomerization of cis- and trans-perhydroindan, we will lump both reactants to a pseudo-component and refer to it simply as perhydroindan in the subsequent discussion.

\subsection{Reactions of perhydroindan on the zeolite catalysts Ir/Na,H-Y, Pt/Na,H-Y, and Pd/Na,H-Beta}

\subsubsection{Activities and overall selectivities}

There was no deactivation of the noble-metal-containing zeolite catalysts under our reaction conditions. In Fig. 1 the conversions of perhydroindan and the product selectivities achieved on the three zeolite catalysts are depicted in dependence of the reaction temperature. It is seen that the catalysts are active in the temperature range from about 200 to $350{ }^{\circ} \mathrm{C}$.

$\mathrm{Ir} / \mathrm{Na}, \mathrm{H}-\mathrm{Y}$ is the most active of the three zeolite catalysts. Up to perhydroindan conversions of about $90 \%$, ring opening is by far the predominant reaction on this catalyst (Fig. 1a). No noticeable skeletal isomerization is observed at any reaction temperature. At elevated temperatures and, hence, conversions, the selectivity of ring-opening products declines, and open-chain nonanes occur in appreciable amounts. At still higher temperatures, hydrocracked products $\left(\mathrm{C}_{8^{-}}\right)$are formed as well.

The results presented in Fig. 1a can be directly compared with those disclosed recently for the hydroconversion of 


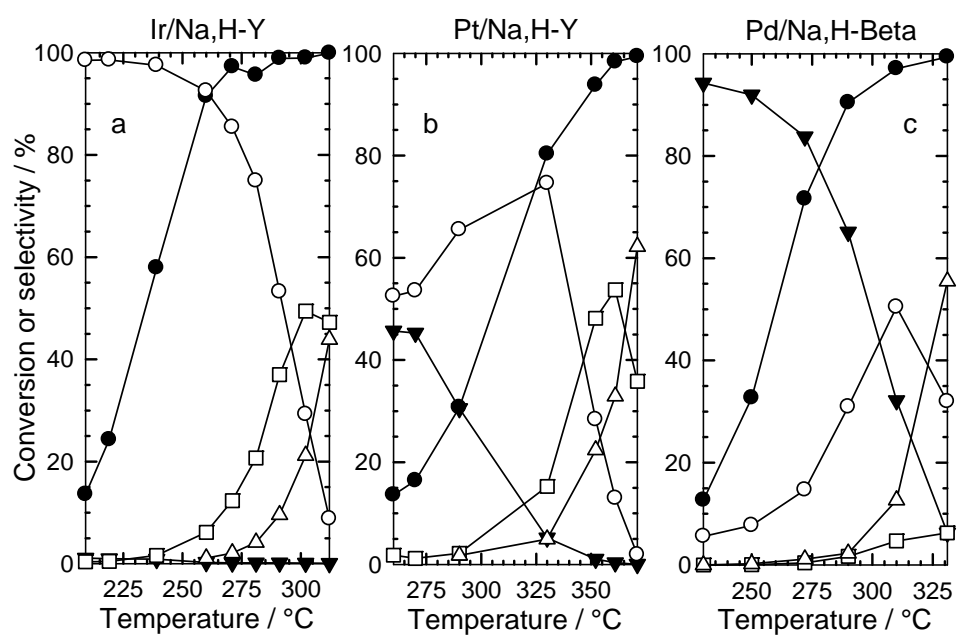

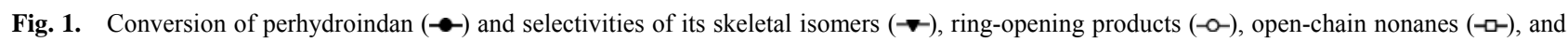
hydrocracked products $\mathrm{C}_{8^{-}}\left(-\Delta_{-}\right)$on the three zeolite catalysts in dependence of the reaction temperature.

decalin [20], since precisely the same $2.9 \mathrm{Ir} / \mathrm{Na}_{0.90}, \mathrm{H}_{0.10}-\mathrm{Y}$ zeolite catalyst was used in both investigations. Perhydroindan turns out to be significantly more reactive than decalin and gives the same conversion at reaction temperatures which are roughly 30 to $50{ }^{\circ} \mathrm{C}$ lower. This difference has its origin in the fast opening of the five-membered ring in perhydroindan, as indicated by the initial selectivity of ring opening products of $98 \%$ (see Fig. 1a) and the fact that the $\mathrm{C}_{9}$ ROPs formed consist almost exclusively of one-ring naphthenes with a remaining six-membered ring (Fig. 2a). In contrast, with decalin as reactant, a lower $S_{\mathrm{ROPS}}=72 \%$ was observed at low conversion [20] reflecting that six-membered rings are more difficult to open by hydrogenolysis on iridium [16]. All these selectivity features indicate that perhydroindan hydroconversion on the $\mathrm{Ir} / \mathrm{Na}, \mathrm{H}-\mathrm{Y}$ zeolite is largely governed by metal catalysis $[16,36]$, as one would expect from the relatively high iridium content, the high dispersion of the metal (Table 1), and the unusually low concentration of Brønsted acid sites.

Particularly noteworthy are the high selectivities of open-chain nonanes that can be attained in the hydroconversion of perhydroindan on Ir/Na,H-Y (see Fig. 1a). At $T=$ $302{ }^{\circ} \mathrm{C} S_{\mathrm{OCNs}}$ is as high as $49 \%$, which is even significantly better than the maximal selectivity of open-chain decanes (OCDs) observed in ring opening of decalin $\left(S_{\mathrm{OCDs}}=36 \%\right.$ at $T=300{ }^{\circ} \mathrm{C}$ ) on the same catalyst [20]. In the complex reaction network of, e.g., perhydroindan hydroconversion, OCNs are formed by opening of the remaining naphthenic ring in ROPs, and the OCNs are consumed by a consecutive hydrocracking to $\mathrm{C}_{8}$ - hydrocarbons. Favorable factors for attaining a high maximum in the measurable OCNs selectivity are, hence, a high rate of ring opening of ROPs and a low rate of hydrocracking of ROPs or OCNs to $\mathrm{C}_{8}$ - Since on $\mathrm{Ir} / \mathrm{Na}, \mathrm{H}-\mathrm{Y}$, opening of the first ring in perhydroindan occurs via hydrogenolysis, it is a straightforward assumption that the same mechanism is responsible for the second
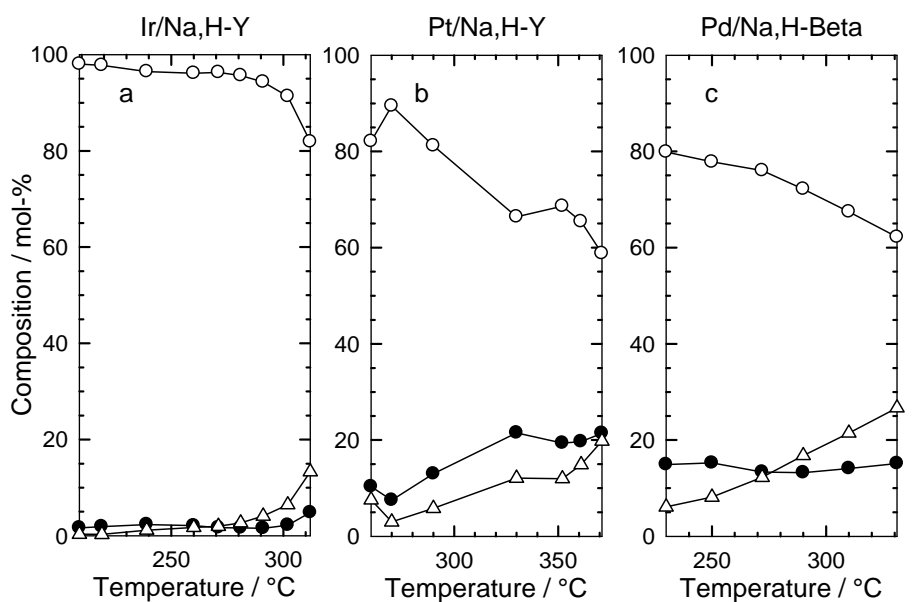

Fig. 2. Ring opening of perhydroindan on the three zeolite catalysts. Breakdown of the ring-opening products into ROPs with a remaining six-membered (-o-) and five-membered ( $\bullet-$ ) ring and into ROPs that have been identified by the molar mass only $(-\triangle)$. 
ring opening of ROPs to OCNs. Also, the consumption of ROPs and OCNs by hydrocracking to $\mathrm{C}_{8^{-}}$occurs through hydrogenolysis, as can be safely concluded for $\mathrm{Ir} / \mathrm{Na}, \mathrm{H}-\mathrm{Y}$ from the hammock-type carbon number distribution curves of the $\mathrm{C}_{8^{-}}$products (vide infra, Fig. 6). It can be expected that ROPs formed from decalin have, on an average, more alkyl substituents on the six-membered ring than ROPs formed from perhydroindan. As shown by McVicker et al. [16] in a comparative investigation of hydroconversion of methylcyclohexane and 1,2,4-trimethylcyclohexane, the rate of ring opening on non-acidic Ir/alumina decreases strongly, as the number of alkyl substituents increases. At the same time ROPs formed from decalin contain more carbon-carbon bonds in the alkyl substituents on the cyclohexane ring, hence the statistical probability for hydrogenolysis in the side chains is higher than in the case of ROPs from perhydroindan.

On the $\mathrm{Ir} / \mathrm{Na}, \mathrm{H}-\mathrm{Y}$ catalyst and with perhydroindan as reactant, at $T=302{ }^{\circ} \mathrm{C}$ and $S_{\mathrm{OCNs}}=49 \%$, the ten most abundant open-chain nonanes were, in the order of their concentrations: 3,4-dimethylheptane (both diastereoisomers), 3ethyl-3-methyl-hexane, 3-ethyl-4-methylhexane, 3,3-dimethylheptane, 4,4-dimethylheptane, 3-ethyl-2-methylhexane, 4-methyloctane, 2,3-dimethylheptane, n-nonane, and 3,5-dimethylheptane (both diastereoisomers).

Typical bifunctional catalysts often possess a metal content of up to ca. $1.0 \mathrm{wt} \%$ and a relatively high concentration of Brønsted acid sites. Examples are $0.85 \mathrm{Ir} / \mathrm{La}_{0.30}, \mathrm{Na}_{0.10}-\mathrm{X}$ or $1.0 \mathrm{Pt} / \mathrm{La}_{0.30}, \mathrm{Na}_{0.10}-\mathrm{X}$ zeolites. It has recently been demonstrated that in ring opening of decalin on such traditional bifunctional catalysts, the maximal yields of open-chain decanes are limited to values of the order of $10 \%$ to $15 \%$ [17]. Much better ring-opening catalysts result if the metal content is increased and the concentration of Brønsted acid sites is decreased significantly [20]. It has been shown using decalin as reactant that on such catalysts, maximal yields of open-chain decanes $Y_{\mathrm{OCD} \text {, } \max }>25 \%$ can be achieved. We refer to catalysts that fulfill this criterion as HIPEROCs. It has now been found that the maximal selectivity of alkanes with the carbon number of the multi-ring naphthene reactant can significantly depend on the nature of this reactant.

The Pt/Na,H-Y catalyst (Fig. 1b) is considerably less active than $\mathrm{Ir} / \mathrm{Na}, \mathrm{H}-\mathrm{Y}$, to reach the same perhydroindan conversion the temperature must be higher by ca. 50 to $80^{\circ} \mathrm{C}$. At variance to $\mathrm{Ir} / \mathrm{Na}, \mathrm{H}-\mathrm{Y}$ zeolite, some skeletal isomerization of the reactant takes place at low conversion and the selectivity of ring-opening products is correspondingly lower. The isomerization of perhydroindan observed on $\mathrm{Pt} / \mathrm{Na}, \mathrm{H}-\mathrm{Y}$ could occur on the noble metal, as it is known in the literature that platinum has the capability to induce skeletal isomerization of hydrocarbons at temperatures around $300{ }^{\circ} \mathrm{C}$ [37] as also found on the non-acidic Pt/silica catalyst (vide infra, Fig. 7b). Alternatively, one could envisage an isomerization via carbocations at the Brønsted acid sites, even though these are present in low concentrations only, as witnessed by the relatively high temperatures at which isomerization occurs. A similar zeolite catalyst, viz. 3.0Pt/Na,H-Y, was recently found to be a high-performance ring-opening catalyst when decalin was used as feed, and it enabled a maximal selectivity of open-chain decanes of 39\% [20]. In the present study with perhydroindan as reactant, 3.7Pt/Na, $\mathrm{H}-\mathrm{Y}$ gave an even much higher maximal selectivity of OCNs amounting to $S_{\mathrm{OCNs}, \max }=54 \%$. Its performance is even slightly better than that of $\mathrm{Ir} / \mathrm{Na}, \mathrm{H}-\mathrm{Y}$ with $S_{\mathrm{OCNs} \text {, } \max }=49 \%$.

The ten most abundant nonane isomers formed on $\mathrm{Pt} / \mathrm{Na}, \mathrm{H}-\mathrm{Y}$ in the order of their concentrations are: 4-methyloctane, 3-methyloctane, n-nonane, 2-methyloctane, 2,5-dimethylheptane, 2,4-dimethylheptane, 3-ethylheptane, 4-ethylheptane, 2,3-dimethylheptane, and 3,3-dimethylheptane. Clearly, the degree of branching in this OCN product mixture is significantly lower compared to the one obtained on Ir/Na,H-Y. These lower degrees of branching are beneficial from the viewpoint of the cetane number of the diesel fuel produced, and they probably have their origin in the different mechanisms of hydrogenolytic ring opening on both metals: Whereas on iridium, naphthenic rings are preferentially opened after the dicarbene mechanism which tends to preserve branchings existing in the naphthenic ring to be opened, hydrogenolysis on platinum shows a much higher contribution of carbon-carbon bond cleavage at tertiary carbon atoms which is associated with the disappearance of branchings [38].

The third zeolite catalyst, $\mathrm{Pd} / \mathrm{Na}, \mathrm{H}-\mathrm{Beta}$, shows a selectivity pattern (Fig. 1c) that differs substantially from those of the two faujasites: Skeletal isomers of perhydroindan strongly dominate at low to moderate conversion, and the selectivity of open-chain nonanes is very low throughout. Since palladium is known to possess a very weak, if any isomerization activity [37,39], a bifunctional mechanism must be invoked for the extremely selective formation of skeletal isomers at low to moderate conversions. Indeed, even though the concentration of Brønsted acid sites on $\mathrm{Pd} / \mathrm{Na}, \mathrm{H}-\mathrm{Beta}$ is not high, these sites are relatively strong as indicated by the adsorption of a good deal of pyridine even at high temperatures. As will be shown below, also the distribution of the hydrocracked products strongly points to a bifunctional mechanism of perhydroindan conversion on $\mathrm{Pd} / \mathrm{Na}, \mathrm{H}-$ Beta zeolite.

\subsubsection{A detailed look at the reactions of perhydroindan}

$\mathrm{Ir} / \mathrm{Na}, \mathrm{H}-\mathrm{Y}$ zeolite is a particularly interesting ring-opening catalyst, not only because it enables high 
yields of open-chain nonanes (or decanes, if decalin is used as feed [20]); it is also well suited for mechanistic studies, since the product distributions generated are not too complex. This, in turn, has its origin in the lack of activity of iridium for skeletal isomerization, its strong preference of hydrogenolytic opening of five-membered over six-membered rings, and the preponderance of the dicarbene mechanism (selective cleavage of bonds between secondary carbon atoms) over the multiplet mechanism (nearly statistical cleavage of all endocyclic carbon-carbon bonds) $[16,38]$. Also, in view of the low reaction temperatures applicable with the highly active $\mathrm{Ir} / \mathrm{Na}, \mathrm{H}-\mathrm{Y}$ catalyst, the principal question arises as to whether or not a bifunctional mechanism via carbocations contributes to the hydroconversion of perhydroindan at all.

According to Fig. 1a ring opening to $\mathrm{C}_{9}$ naphthenes with a single ring is by far the predominant reaction of perhydroindan on $\mathrm{Ir} / \mathrm{Na}, \mathrm{H}-\mathrm{Y}$ zeolite at conversions up to ca. $90 \%$. Figure 2a impressively shows that, on this catalyst, the five-membered ring in perhydroindan is opened almost exclusively, i.e., $\mathrm{C}_{9}$ ROPs with a remaining cyclohexane ring are formed, whereas $\mathrm{C}_{9}$ ROPs with a remaining cyclopentane ring occur to a negligible extent. In addition, small amounts of $\mathrm{C}_{9}$ ROPs have been formed that were identified by the molecular ion $(126 \mathrm{~g} / \mathrm{mol})$ in the mass spectrum of the GC-MS analysis only, it is hence unknown whether the remaining naphthenic ring is six- or five-membered. We speculate that these unidentified $\mathrm{C}_{9}$ ROPs are, to a large extent, molecules with a five-membered ring, formed by carbocationic isomerization of ROPs with a six-membered ring. Their formation at high conversions would explain the higher yields of open-chain nonanes formed on $\mathrm{Ir} / \mathrm{Na}, \mathrm{H}-\mathrm{Y}$ in comparison to the non-acidic Ir/silica catalyst (see Sec- tion 2.4) which is not able to isomerize six-membered rings to five-membered rings, the latter being known to be opened much faster than six-membered rings by hydrogenolysis [16].

On $\mathrm{Pt} / \mathrm{Na}, \mathrm{H}-\mathrm{Y}$ and $\mathrm{Pd} / \mathrm{Na}, \mathrm{H}-\mathrm{Beta}$ by contrast, the six-membered ring is opened already at low conversions, albeit to a small extent, see Figs. $2 \mathrm{~b}$ and $2 \mathrm{c}$. On these catalysts, $8 \%$ to $21 \%$ of all $\mathrm{C}_{9}$ ROPs contain a five-membered ring. Moreover, roughly similar amounts of unidentified $\mathrm{C}_{9}$ ROPs are formed on these two catalysts with a noticeable isomerization activity, which are presumably mainly ROPs with a five-membered ring, since the larger number of carbon atoms in the alkyl side chains allows a larger variety of skeletal isomers and renders peak assignment by GC-MS difficult. For the formation of such molecules three different reaction pathways are possible: (i) A hydrogenolytic ring opening of the six-membered ring in perhydroindan, (ii) a ring opening of skeletal isomers of perhydroindan, or (iii) the skeletal isomerization of ROPs with a six-membered to ROPs with a five-membered ring.

As depicted in Fig. 3, opening of the five-membered ring in perhydroindan can principally result in three $\mathrm{C}_{9}$ ROPs, viz. 1-ethyl-2-methylcyclohexane or propylcyclohexane and cyclononane. The first-mentioned hydrocarbon forms by hydrogenolysis via the dicarbene mechanism (breaking of bonds between secondary, unsubstituted carbon atoms), whereas hydrogenolysis via the multiplet mechanism would be expected to give 1-ethyl-2-methylcyclohexane, propylcyclohexane, and, perhaps, cyclononane. No cyclononane was found in the products on Ir/Na,H-Y zeolite by GC-MS analysis, but it cannot be ruled out that traces of the compound have been formed. Propylcyclohexane did occur, but only in very small amounts $\left(S_{\mathrm{P}-\mathrm{CHx}}<<S_{1-\mathrm{E}-2-\mathrm{M}-\mathrm{CHx}}\right)$. Unfortu-

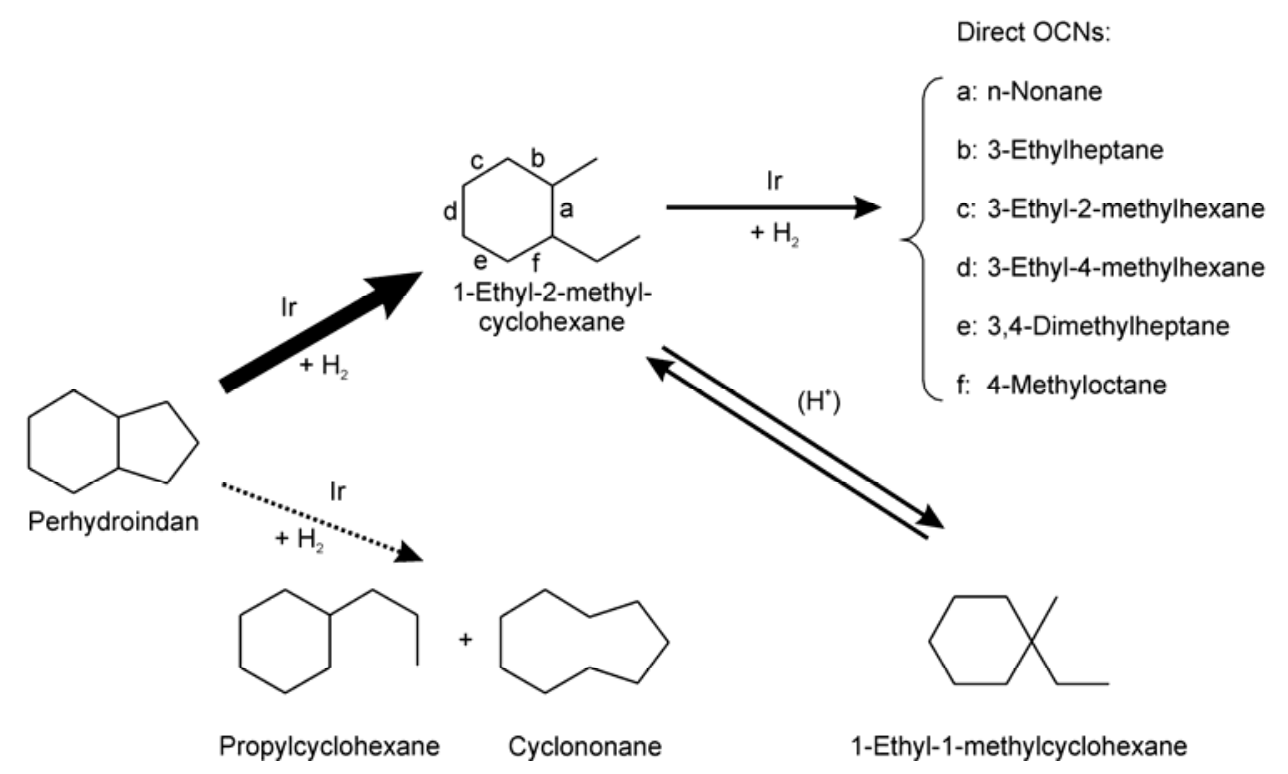

Fig. 3. Opening of the five-membered ring in perhydroindan and consecutive reactions on the $\mathrm{Ir} / \mathrm{Na}, \mathrm{H}-\mathrm{Y}$ catalyst. 
nately, on the Supelco Petrocol DH 150 capillary column, the peak for propylcyclohexane appears very shortly after that of cis-1-ethyl-2-methylcyclohexane, hence small amounts of propylcyclohexane cannot be reliably quantified, if the peak of cis-1-ethyl-2-methylcyclohexane is large. Exactly this was the case in the chromatograms of the products on $\mathrm{Ir} / \mathrm{Na}, \mathrm{H}-\mathrm{Y}$ zeolite, confirming the expectation $[16,38]$ that hydrogenolytic ring cleavage of perhydroindan on that catalyst proceeds selectively via the dicarbene mechanism.

At elevated temperatures and conversions, the dominating primary product of ring opening, i.e. 1-ethyl-2-methylcyclohexane, can undergo secondary reactions on $\mathrm{Ir} / \mathrm{Na}, \mathrm{H}-\mathrm{Y}$ zeolite. In particular, opening of the six-membered ring begins to occur at ca. $250^{\circ} \mathrm{C}$, as has been shown by hydroconverting decalin on the same catalyst [20]. The six predicted open-chain nonane isomers are listed in Fig. 3. For example, at $T=260^{\circ} \mathrm{C}$, these six nonane isomers account for $72 \%$ of the OCNs formed on Ir/Na,H-Y. The six-membered ring in 1-ethyl-2-methylcyclohexane is preferentially opened at the bisecondary positions $\mathrm{c}, \mathrm{d}$, and $\mathrm{e}$ (see Fig. 3) leading to 3-ethyl-2-methylhexane, 3-ethyl-4methylhexane, and 3,4-dimethylheptane, respectively, thereby confirming again the preference of iridium for hydrogenolysis after the dicarbene mechanism [16,38]. At higher conversions the fraction of these six direct OCNs in the product group of OCNs decreases, and at the temperature of maximal $\mathrm{OCN}$ yield $\left(T=302{ }^{\circ} \mathrm{C}\right)$ only $51 \%$ of all nonane isomers consist of the six ones mentioned in Fig. 3. This indicates that, at such high conversions, the direct hydrogenolysis of the five-membered and subsequently of the six-membered ring of perhydroindan is no longer the only reaction path to OCNs. In particular, we believe that some bifunctional isomerization takes place on $\mathrm{Ir} / \mathrm{Na}, \mathrm{H}-\mathrm{Y}$ at elevated temperatures, and the skeletal isomers of perhydroindan thereby formed undergo a rapid hydrogenolysis to other nonane isomers.
By the ancillary GC-MS analyses of the liquid samples, another hydrocarbon could be identified as a product of perhydroindan conversion on the $\mathrm{Ir} / \mathrm{Na}, \mathrm{H}-\mathrm{Y}$ catalyst, viz. 1-ethyl-1-methylcyclohexane. It begins to form at reaction temperatures as low as $240^{\circ} \mathrm{C}$ and can be looked upon as a consecutive product of 1-ethyl-2-methylcyclohexane (Fig. 3). As shown in Fig. 4, the selectivity of 1-ethyl-1-methylcyclohexane passes through a maximum at $291{ }^{\circ} \mathrm{C}$, and two other $\mathrm{C}_{9}$ hydrocarbons begin to appear in the product, namely 3-ethyl-3-methylhexane and 3,3-dimethylheptane.

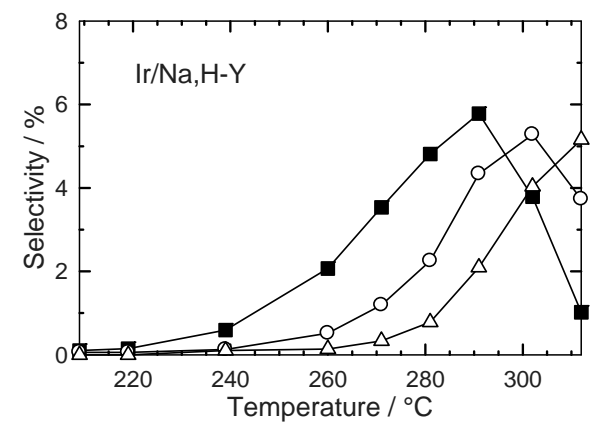

Fig. 4. Formation of 1-ethyl-1-methylcyclohexane (-a), 3-ethyl-3methylhexane $(-\infty)$, and 3,3-dimethylheptane $(-\Delta)$ in the hydroconversion of perhydroindan on $\mathrm{Ir} / \mathrm{Na}, \mathrm{H}-\mathrm{Y}$ zeolite.

Probably the best way to account for the formation of 1-ethyl-1-methylcyclohexane is to invoke an isomerization of 1-ethyl-2-methylcyclohexane on the Brønsted acid sites of the catalyst via carbocations (Fig. 5). This is a so-called type A rearrangement in which the number of branchings in the carbocation remains constant, just their positions change [40].

Support for such a mechanism stems from the fact that type A skeletal rearrangements are among the most facile and rapid reactions in carbenium ion chemistry, and the relatively low concentration and strength of the Brønsted acid sites in Ir/Na,H-Y zeolite may just be appropriate to enable such rearrangements at temperatures around $250{ }^{\circ} \mathrm{C}$.

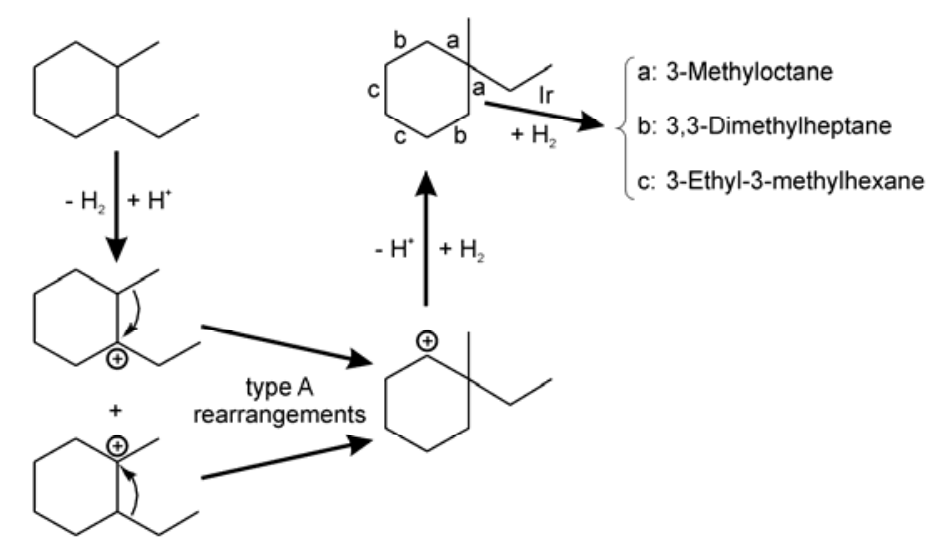

Fig. 5. Proposed type A isomerization of 1-ethyl-2-methylcyclohexane into 1-ethyl-1-methylcyclohexane via carbocations on the Brønsted acid sites of Ir/Na,H-Y zeolite followed by hydrogenolysis of 1-ethyl-1-methylcyclohexane on iridium. 
Moreover, a completely analogous skeletal isomerization has been observed with decalin as reactant on the same catalyst and at the same temperature, namely the formation of spiro[4.5]decane [20].

If the reasonable assumption is made that, because of their high ring strain, no four-membered naphthenic rings are formed, then a single product of cationic type A isomerization of perhydroindan is expected, namely spiro[4.4]nonane. In fact, if decalin is used as reactant and if the catalyst contains Brønsted acid sites, the analogous product spiro[4.5]decane does form at low conversions, as shown recently [17]. We hence made an attempt to find out whether spiro[4.4]nonane occurred as a primary product of perhydroindan conversion. On $\mathrm{Pd} / \mathrm{Na}, \mathrm{H}-\mathrm{Beta}$ and $\mathrm{Pt} / \mathrm{Na}, \mathrm{H}-\mathrm{Y}$ two skeletal isomers $(M=124 \mathrm{~g} / \mathrm{mol})$ were indeed formed at low conversions with combined selectivities of up to $67 \%$ which were eluted from the capillary column in the range of retention times which was considered to be consistent with the published boiling point of spiro[4.4]nonane $\left(156\right.$ to $\left.157^{\circ} \mathrm{C}[41,42]\right)$. As another piece of information, the two sk-Isos in question were not formed to a significant extent on the non-acidic silica-supported catalysts. Finally, we plotted the selectivities of the two sk-Isos versus the perhydroindan conversion (not shown) and compared the results with the analogous plot of $S_{\text {spiro[4.5]decane }}$ against $X_{\text {decalin }}$ for the same catalysts. For one of the two unidentified sk-Isos of perhydroindan the selectivity plot against $X_{\mathrm{PHI}}$ strongly resembled the one for $S_{\text {spiro[4.5]decane }}$ versus $X_{\text {decalin }}$. We conclude that, even though the peak assignment of the peak in question is not safe, evidence exists for spiro[4.4]nonane being formed from perhydroindan along a cationic reaction path, if the catalyst contains Brønsted acid sites.

In Fig. 6 the modified hydrocracking selectivities as de-

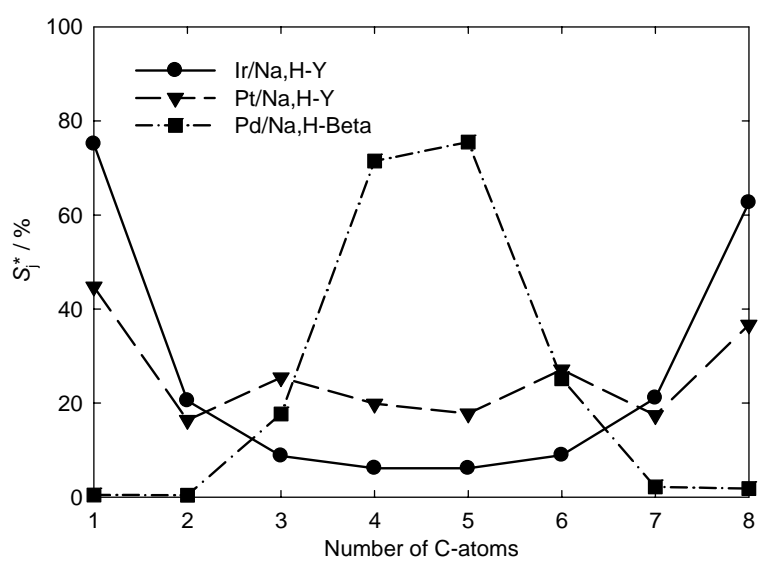

Fig. 6. Modified hydrocracking selectivities $S_{\mathrm{j}}{ }^{*}$ in the hydroconversion of perhydroindan on the three zeolite catalysts. Ir/Na,H-Y: $T_{\mathrm{r}}=$ $302{ }^{\circ} \mathrm{C}, X_{\mathrm{PHI}}=99 \%, Y_{\mathrm{C}_{8^{-}}}=21 \%$; Pt/Na,H-Y: $T_{\mathrm{r}}=361{ }^{\circ} \mathrm{C}, X_{\mathrm{PHI}}=98 \%$, $Y_{\mathrm{C}_{8^{-}}}=32 \%$; Pd/Na,H-Beta: $T_{\mathrm{r}}=331^{\circ} \mathrm{C}, X_{\mathrm{PHI}}=99 \%, Y_{\mathrm{C}_{8^{-}}}=55 \%$. fined in Section 1.3 are shown for perhydroindan hydroconversion on the three zeolite catalysts at moderate yields of hydrocracked products. Mainly $\mathrm{C}_{1}$ and $\mathrm{C}_{8}$ beside less $\mathrm{C}_{2}$ and $\mathrm{C}_{7}$ and little $\mathrm{C}_{3}$ to $\mathrm{C}_{6}$ hydrocarbons are formed on $\mathrm{Ir} / \mathrm{Na}, \mathrm{H}-\mathrm{Y}$ zeolite. Very similar distribution curves were observed for hydrocracking of decalin on $\mathrm{Ir} / \mathrm{Na}, \mathrm{H}-\mathrm{Y}$ catalysts [20]. It has been discussed previously [18-20] that such hammock-shaped curves can only be rationalized in terms of a formation of the hydrocracked products via hydrogenolysis on iridium. Similarly, hydrocracking of perhydroindan on $\mathrm{Pt} / \mathrm{Na}, \mathrm{H}-\mathrm{Y}$ results in a distribution curve that resembles the one found for decalin hydroconversion on a very similar catalyst [20]. This type of $S_{\mathrm{j}}^{*}$ curves, too, is mainly indicative of a hydrogenolysis on the noble metal, but it cannot be ruled out that at the higher temperatures needed for $\mathrm{C}_{8}$ - formation on $\mathrm{Pt} / \mathrm{Na}, \mathrm{H}-\mathrm{Y}$, some bifunctional hydrocracking is superimposed to hydrogenolysis [20].

A principally different distribution curve results for hydrocracking of perhydroindan on $\mathrm{Pd} / \mathrm{Na}, \mathrm{H}-\mathrm{Beta}$ : This curve is volcano-shaped with no $\mathrm{C}_{1}$ and $\mathrm{C}_{2}$ and very little $\mathrm{C}_{7}$ and $\mathrm{C}_{8}$. Mainly $\mathrm{C}_{4}$ and $\mathrm{C}_{5}$ moieties are formed, besides $\mathrm{C}_{3}$ and $\mathrm{C}_{6}$ hydrocarbons occur to a much lesser extent. The $\mathrm{C}_{4}$ fraction consists of $n$-butane (22 mol\%) and iso-butane ( $78 \mathrm{~mol} \%)$, the $\mathrm{C}_{5}$ fraction of $n$-pentane $(27 \mathrm{~mol} \%)$, 2-methylbutane (55 mol\%), and cyclopentane (18 mol\%), and the $\mathrm{C}_{6}$ fraction of $\mathrm{n}$-hexane $(11 \mathrm{~mol} \%)$, methylpentanes (28 mol\%), 2,2-dimethylbutane (2 mol\%), methylcyclopentane $(49 \mathrm{~mol} \%)$, and cyclohexane $(10 \mathrm{~mol} \%)$. Very similar product distributions have been reported for hydrocracking of one-ring naphthenes with nine carbon atoms, such as 1,2,4-trimethylcyclohexane [43] or propylcyclohexane [44] on bifunctional catalysts like NiS/silica-alumina or Pd/La-Y, respectively. Even the slight asymmetry of the distribution curve with $S_{\mathrm{C}_{5}}>S_{\mathrm{C}_{4}}, S_{\mathrm{C}_{6}}>S_{\mathrm{C}_{3}}$ and some small amounts of $\mathrm{C}_{7}$ and $\mathrm{C}_{8}$ was observed in these prior studies with bifunctional catalysts $[43,44]$ and attributed to the occurrence of cationic disproportionation-type side reactions. It is also noteworthy that the product distributions observed on $\mathrm{Pd} / \mathrm{Na}, \mathrm{H}-\mathrm{Y}$, especially the relatively large amounts of $\mathrm{C}_{5}$ and $\mathrm{C}_{6}$ naphthenes, are not consistent with a bifunctional hydrocracking mechanism starting from open-chain nonanes $[45,46]$. Rather, hydrocracking of $\mathrm{C}_{9}$ one-ring naphthenes seems to be the main reaction path.

We are hence led to conclude that, in the hydroconversion of perhydroindan, $\mathrm{Pd} / \mathrm{Na}, \mathrm{H}-\mathrm{Beta}$ zeolite acts predominantly as a bifunctional catalyst, and the main role of the noble metal is to enable the interconversion of cycloalkanes and cycloalkenes. In particular, the highly selective skeletal isomerization of the bicyclic reactant at low and medium conversion (see Fig. 1c) as well as the hydrocracking to $\mathrm{C}_{8^{-}}$ hydrocarbons are believed to occur mainly via carbocations on the acid sites. Also consistent with a cationic reaction 
path is the possible formation of spiro[4.4]nonane (vide supra) with the highest selectivity on $\mathrm{Pd} / \mathrm{Na}, \mathrm{H}-\mathrm{Beta}$. It is less clear, however, whether the first ring opening reaction from sk-Isos to ROPs takes place via carbocations on the acid sites as well or via hydrogenolysis on palladium.

\subsection{Reactions of perhydroindan on Ir/silica, Pt/silica, and Pd/silica}

Shown in Fig. 7 are the conversions of perhydroindan and the selectivities of the various product groups on the three silica-supported metal catalysts in dependence of the reaction temperature. Since the support lacks acid properties (cf. Section 2.1), it is straightforward to interpret the results in terms of pure metal catalysis. Table 1 shows that the metal contents of the three catalysts are approximately the same, so the following activity sequence can be deduced from Fig. 7 for perhydroindan hydroconversion: $\mathrm{Ir}>\mathrm{Pt}>\mathrm{Pd}$. This is in accordance with literature data, e.g. for the hydrogenolysis of $n$-heptane [37]. If compared to the $\mathrm{Ir} / \mathrm{Na}, \mathrm{H}-\mathrm{Y}$ and $\mathrm{Pt} / \mathrm{Na}, \mathrm{H}-\mathrm{Y}$ catalysts (Figs. 1a and $1 \mathrm{~b}$ ), the silica-supported counterparts (Figs. 7a and 7b) are less active which may be due to the lower metal content of the latter and/or an activity-enhancing effect of the mild acidity in the two faujasite catalysts. As a comparison of Figs. 1c and 7c shows, $\mathrm{Pd} /$ silica is significantly less active than $\mathrm{Pd} / \mathrm{Na}, \mathrm{H}-\mathrm{Beta}$ zeolite.

The product selectivities observed on Ir/silica resemble those observed for Ir/Na,H-Y zeolite: No skeletal isomerization of perhydroindan occurs, rather ring opening strongly dominates the selectivity pattern up to conversions of ca. $80 \%$. At severe reaction conditions, open-chain decanes are formed, but upon further increasing the temperature they are rapidly consumed by the undesired hydrocracking to $\mathrm{C}_{8}$ hydrocarbons. Comparing Figs. 1a and 7a impressively shows that using a high metal content and adding a mildly acidic catalyst component to an iridium catalyst helps to improve the selectivity and yield of the desired open-chain nonanes. On Pt/silica at significantly higher temperatures (Fig. 7b), the selectivity pattern is not too different from the one on Ir/silica: ring opening strongly prevails, but the selectivity of ROPs is slightly lower than on Ir/silica reflecting that platinum isomerizes perhydroindan, albeit with a low selectivity of ca. $8 \%$ at low conversion. Comparing Figs. $1 \mathrm{~b}$ and $7 \mathrm{~b}$ demonstrates that, for a platinum catalyst too, adding a weakly Brønsted-acidic component brings about a considerable improvement in the selectivity of OCNs. Pd/silica (Fig. 7c) behaves principally different than the same metal on a strongly acidic zeolite (Fig. 1c). Palladium on a non-acidic carrier is remarkably inactive in skeletal isomerization and ring opening of perhydroindan (Fig. 7c). It is, however, an efficient catalyst for its dehydrogenation to indan with a maximal molar fraction $n_{\text {indan }} /\left(n_{\mathrm{PHI}}+n_{\text {indan }}\right)=$ $46 \%$ and traces of indene at the maximal reaction temperature of $410{ }^{\circ} \mathrm{C}$. This is probably not far from the position of the dehydrogenation/hydrogenation equilibrium and in the same order of magnitude as data published by Nylén et al. [25] and Rao et al. [26]. These authors converted indan on an Ir,Pt/boehmite catalyst at a hydrogen pressure of 4.0 MPa.

A closer look at the ring-opening products formed on the three metals (Fig. 8) shows that endocyclic hydrogenolysis of the five-membered ring is clearly preferred. This is particularly true for iridium (Fig. 8a) where the ring opening results almost exclusively in naphthenes with a remaining six-membered ring. The reasons for the peculiar behavior of the data points at the two highest temperatures are unknown. This extreme preference for breaking the five-membered ring is usually interpreted in terms of a higher ring strain in five-membered compared to

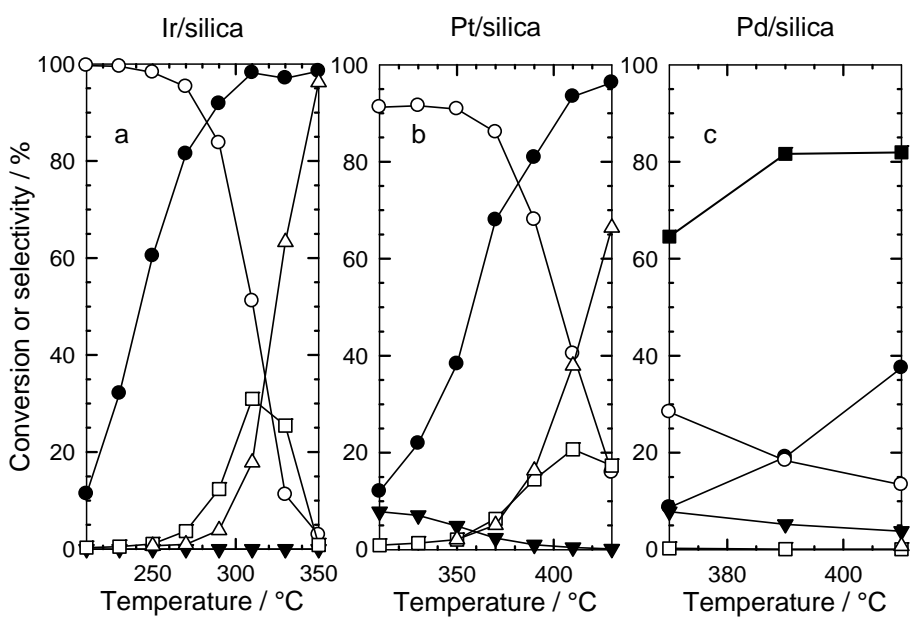

Fig. 7. Conversion of perhydroindan (-) and selectivities of its skeletal isomers $(-\boldsymbol{-})$, ring-opening products ( - - $)$, open-chain nonanes $(-\square)$, hydrocracked products $\mathrm{C}_{8^{-}}\left(-\Delta_{-}\right)$, and dehydrogenated products $(-\mathbf{-})$ on the three silica-supported catalysts in dependence of the reaction temperature. 


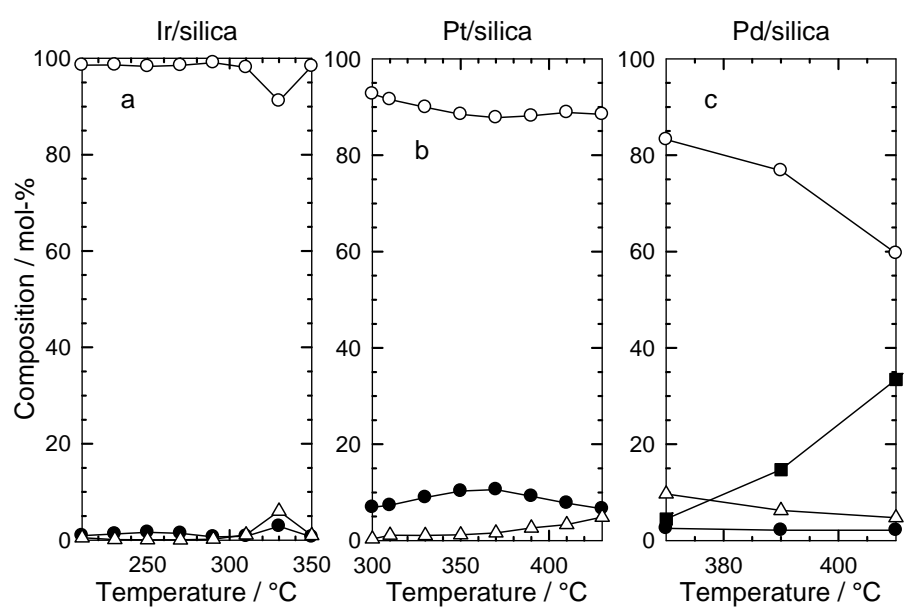

Fig. 8. Ring opening of perhydroindan on the three silica-supported catalysts. Breakdown of the ring-opening products into ROPs with a remaining six-membered (-o-), with a remaining five-membered ( $\bullet-)$ ring, into ROPs that have been identified by the molar mass of $M=126 \mathrm{~g} / \mathrm{mol}$ only $(-\triangle)$, and into ROPs with an aromatic ring $(--)$.

six-membered rings [16,48]. On platinum this preference is less pronounced than on iridium, up to $11 \%$ of all ROPs contain a five-membered ring. It might also be that the higher temperatures that had to be applied with the platinum catalyst facilitate opening of the six-membered ring.

Only small selectivities of ROPs between $13 \%$ and $27 \%$ were reached on $\mathrm{Pd} /$ silica, see Fig. 7c. They are composed mainly of ROPs with a remaining saturated six-membered ring (Fig. 8c) and the corresponding aromatics which are formed in substantial amounts and make up 33\% of all ROPs at $410{ }^{\circ} \mathrm{C}$. Out of the six tested catalysts, $\mathrm{Pd} /$ silica is the only one on which the formation of aromatic ROPs was observed. This is in accordance with the low activity of the catalyst in general together with the high reaction temperatures that led also to large amounts of the DHPs indan and indene, see Fig. 7c. Also some ROPs are formed on all three catalysts which cannot be assigned to particular molecules but were assigned to the product group of ROPs by GC-MS due to their molecular ion signal but they contribute only to a very small extent on $\mathrm{Ir} /$ silica and $\mathrm{Pt} /$ silica. On $\mathrm{Pd} /$ silica up to $10 \%$ of all ROPs are unidentified, but due to the small ring-opening selectivity the total amount of these products is unimportant.

Iridium on non-acidic silica turns out to be a particularly suitable catalyst for studying hydrogenolytic ring-opening reactions, because no isomerization of the carbon skeleton takes place prior to or after the carbon-carbon bond cleavage step. In all experiments within the temperature range from 210 to $310{ }^{\circ} \mathrm{C}$ the molar fraction of cis- and trans-1-ethyl-2-methylcyclohexane in the total ring-opening products amounted to values between $96 \%$ and $100 \%$. This shows to what extent iridium prefers the dicarbene mechanism of hydrogenolysis [16,38]. Using Pt/silica and $\mathrm{Pd} /$ silica, this molar fraction assumed values between $34 \%$ and $61 \%$ only. This is partly due to the opening of the six-membered ring in perhydroindan, partly to the occurrence of hydrogenolysis at substituted carbon-carbon bonds according to the multiplet mechanism which is well known to operate on highly dispersed platinum [38], and partly to the mild skeletal isomerization activity of platinum and palladium. Given the extremely high selectivity for the ring-opening product 1-ethyl-2-methylcyclohexane on $\mathrm{Ir} /$ silica, one expects the formation of open-chain nonanes to occur by a second hydrogenolysis step starting from this particular $\mathrm{C}_{9}$ naphthene. The six predicted open-chain nonane isomers are listed in Fig. 3. Indeed, at a reaction temperature of $310{ }^{\circ} \mathrm{C}$ the maximal selectivity and yield of these OCN isomers ("direct OCNs") accounted for $92 \%$ of all OCNs formed. Of these $60 \%$ were the dibranched isomers 3-ethyl-2-methylhexane, 3-ethyl-4-methylhexane, and 3,4-dimethylheptane, and $40 \%$ the isomers $n$-nonane, 3-ethylheptane, and 4-methyloctane. In other words, hydrogenolysis occurred not only at bonds c, d, and e (cf. Fig. 3), as one would expect after the dicarbene mechanism, but also at bonds $a, b$, and $f$. Such a ring cleavage of bonds between substituted carbon atoms is best accounted for by a mechanism introduced by Maire et al. [38] and named "partially selective mechanism" which was later referred to as "metallacyclobutane mechanism" [49]. It is known to become operative at the higher temperatures required for the more demanding hydrogenolysis of six-membered naphthenic rings, especially if the number of alkyl substituents increases, and it was also invoked by McVicker et al. [16] for the hydrogenolysis of 1,2,4-trimethylcyclohexane on an Ir/alumina catalyst.

It is noteworthy from a mechanistic point of view that virtually no 1 -ethyl-1-methylcyclohexane $(S \leq 0.1 \%)$ was formed on Ir/silica. This supports the view that this product 
is formed on $\mathrm{Ir} / \mathrm{Na}, \mathrm{H}-\mathrm{Y}$ zeolite from 1-ethyl-2-methylcyclohexane via skeletal type $\mathrm{A}$ isomerization on the acid sites (see Section 2.3.2).

From a practical viewpoint, the alkanes produced by ring opening should not have a too high degree of branching because this has a negative influence on the cetane number. Figure 9 shows that Ir/silica tends to produce much larger amounts of multiply branched nonanes compared to $\mathrm{Pt} /$ silica, from the viewpoint of the diesel fuel ignition characteristics the latter catalyst seems to be more favorable.

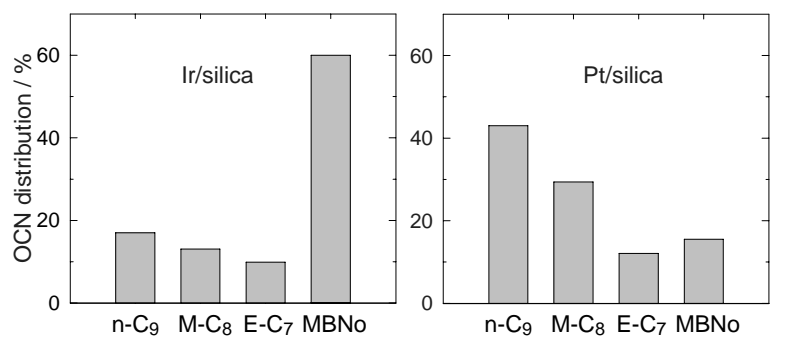

Fig. 9. Hydrodecyclization of perhydroindan on non-acidic Ir/silica and $\mathrm{Pt} /$ silica. Breakdown of the differently branched open-chain nonanes at maximal selectivities of OCNs. E: ethyl; M: methyl; MBNo: multiply branched iso-nonanes.

Figure 10 displays the carbon number distributions of the $\mathrm{C}_{8^{-}}$products formed on the noble-metal catalysts with non-acidic silica as support. For Ir/silica and Pt/silica, the experiments with maximal selectivities of open-chain nonanes and moderate selectivities of hydrocracked products were chosen. As on Ir/Na,H-Y (Fig. 6), a typical hammock-type distribution curve is obtained on $\mathrm{Ir} /$ silica. It is obvious that on both iridium catalysts the $\mathrm{C}_{8^{-}}$hydrocarbons are formed via hydrogenolysis on the metal. Essentially the same hammock-type curve results on $\mathrm{Pd} /$ silica, hydro-

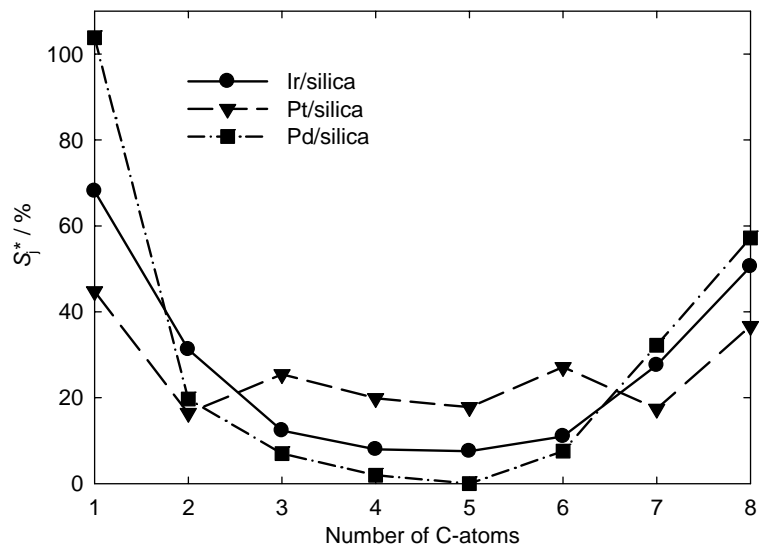

Fig. 10. Modified hydrocracking selectivities $S_{\mathrm{j}}{ }^{*}$ in the hydroconversion of perhydroindan on the three silica-supported catalysts. Ir/silica: $T_{\mathrm{r}}=310^{\circ} \mathrm{C}, X_{\mathrm{PHI}}=98 \%, Y_{\mathrm{C}_{8^{-}}}=18 \%$; Pt/silica: $T_{\mathrm{r}}=410^{\circ} \mathrm{C}, X_{\mathrm{PHI}}=93 \%$ $Y_{\mathrm{C}_{8^{-}}}=35 \%$; Pd/silica: $T_{\mathrm{r}}=410^{\circ} \mathrm{C}, X_{\mathrm{PHI}}=37 \%, Y_{\mathrm{C}_{8^{-}}}=0.3 \%$. genolysis seems to be the pathway for $\mathrm{C}_{8^{-}}$formation on this catalyst as well. Of great relevance is the finding that the distribution curve for Pt/silica (Fig. 10) is almost identical to the one for $\mathrm{Pt} / \mathrm{Na}, \mathrm{H}-\mathrm{Y}$ zeolite (Fig. 6). Since Pt/silica is a totally non-acidic catalyst, this near-identitiy of the $S_{\mathrm{j}}{ }^{*}$ curves is a strong argument for invoking a hydrogenolytic reaction path for the formation of $\mathrm{C}_{8^{-}}$hydrocarbons on $\mathrm{Pt} / \mathrm{Na}, \mathrm{H}-\mathrm{Y}$.

\section{Conclusions}

Perhydroindan is an attractive model hydrocarbon for investigating the reaction paths in the catalytic hydrodecyclization of multi-ring naphthenes. Its salient structural feature is the simultaneous occurrence of a six-membered and a five-membered naphthenic ring. Opening of these rings can happen with very different rates, the most striking example being the pronounced selectivity of metallic iridium for hydrogenolytic cleavage of carbon-carbon bonds that form part of a five-membered ring. As a whole, the results obtained in the catalytic ring opening of perhydroindan can nicely supplement those that are typically gained in the hydrodecyclization of decalin, the most widely used model hydrocarbon in catalytic ring-opening studies.

Representatives of three classes of ring-opening catalysts were used in this study, namely a typical bifunctional zeolite ( $\mathrm{Pd} / \mathrm{Na}, \mathrm{H}-\mathrm{Beta})$, two zeolitic high-performance ring-opening catalysts (HIPEROCs, Ir/Na,H-Y, and $\mathrm{Pt} / \mathrm{Na}, \mathrm{H}-\mathrm{Y}$ ) [20], and the three noble metals on a support lacking Brønsted acid sites (Ir/silica, Pt/silica, and $\mathrm{Pd} /$ silica). Perhydroindan was converted on these catalysts under a hydrogen pressure of $5 \mathrm{MPa}$. The typical bifunctional zeolite allows opening of one ring in perhydroindan with selectivities of ca. $50 \%$, but the selectivity of open-chain nonanes is poor, confirming the results previously obtained with bifunctional faujasites and decalin as model hydrocarbon [17]. Excellent selectivities of ring-opening products $\left(\mathrm{C}_{9}\right.$ one-ring naphthenes plus open-chain nonanes) were achieved on the $\mathrm{Ir} / \mathrm{Na}, \mathrm{H}-\mathrm{Y}$ and $\mathrm{Pt} / \mathrm{Na}, \mathrm{H}-\mathrm{Y}$ zeolites at perhydroindan conversions of nearly $100 \%$. The maximum selectivities and yields of open-chain nonanes alone were $49 \%$ and $54 \%$ on $\mathrm{Ir} / \mathrm{Na}, \mathrm{H}-\mathrm{Y}$ and $\mathrm{Pt} / \mathrm{Na}, \mathrm{H}-\mathrm{Y}$, respectively, and significantly higher than the corresponding values of open-chain decanes in the conversion of decalin observed in a previous study [20].

Of the three noble-metal catalysts with a non-acidic support, $\mathrm{Pd} /$ silica is rather inactive in ring opening, the main reactions being dehydrogenation to indan at temperatures around $400{ }^{\circ} \mathrm{C}$. By contrast, Ir/silica is highly active in ring opening of perhydroindan already at temperatures of ca. 250 to $300{ }^{\circ} \mathrm{C}$. It opens the five-membered naphthenic ring to 1-ethyl-2-methylcyclohexane, according to the dicarbene 
mechanism which is well known from prior hydrogenolysis studies on iridium-based catalysts. Pt/silica is less active and catalyzes, in addition, skeletal isomerization, opening of the six-membered ring and endocyclic hydrogenolysis at substituted carbon-carbon bonds leading to less branched open-chain nonanes. A comparison of the carbon-number distribution of the hydrocracked products formed on $\mathrm{Pt} /$ silica with those obtained on $\mathrm{Pt} / \mathrm{Na}, \mathrm{H}-\mathrm{Y}$ reveals that hydrocracking to $\mathrm{C}_{8^{-}}$on HIPEROCs is governed by hydrogenolysis on the noble metal.

We believe that, on HIPEROCs, hydrogenolysis on iridium or platinum plays an important role as well in the key steps of hydrodecyclization, i.e. the ring opening of perhydroindan or sk-Isos to ROPs and further on of ROPs to OCNs. The presence of Brønsted acid sites, however, is crucial as well, if one aims at high selectivities of OCNs. This is obvious from a comparison of the results obtained on the $\mathrm{Ir} / \mathrm{Na}, \mathrm{H}-\mathrm{Y}$ and $\mathrm{Pt} / \mathrm{Na}, \mathrm{H}-\mathrm{Y}$ zeolites with those attained on the silica-supported metals.

\section{References}

1 Santana R C, Do P T, Santikunaporn M, Alvarez W E, Taylor J D, Sughrue E L, Resasco D E. Fuel, 2006, 85: 643

2 Weitkamp J. In: Ertl G, Knözinger H, Schüth F, Weitkamp J ed. Handbook of Heterogeneous Catalysis. 2nd Ed. Vol. 7. Weinheim: Wiley-VCH, 2008. 3133

3 Kubička D, Kumar N, Mäki-Arvela P, Tiitta M, Niemi V, Salmi T, Murzin D Y. J Catal, 2004, 222: 65

4 Santikunaporn M, Herrera J E, Jongpatiwut S, Resasco D E, Alvarez W E, Sughrue E L. J Catal, 2004, 228: 100

5 Arribas M A, Martínez A, Sastre G. Stud Surf Sci Catal, 2002, 142: 1015

6 Arribas M A, Concepción P, Martínez A. Appl Catal A, 2004, 267: 111

7 Arribas M A, Corma A, Díaz-Cabañas M J, Martínez A. Appl Catal A, 2004, 273: 277

8 Kubička D, Kumar N, Mäki-Arvela P, Tiitta M, Niemi V, Karhu H, Salmi T, Murzin D Y. J Catal, 2004, 227: 313

9 Kumar N, Lazuen A, Kubička D, Heikkilä T, Lehto V-P, Karhu H, Salmi T, Murzin D Y. Stud Surf Sci Catal, 2006, 162: 401

10 Ma H, Yang X, Wen G, Tian G, Wang L, Xu Y, Wang B, Tian Z, Lin L. Catal Lett, 2007, 116: 149

11 Mouli K C, Sundaramurthy V, Dalai A K, Ring Z. Appl Catal A, 2001, 321: 17

12 Murzin D Y, Kubička D, Simakova II L, Kumar N, Lazuen A, Mäki-Arvela P, Tiitta M, Salmi T. Pet Chem (Neftekhimiya), 2009, 49: 90

13 Kumar N, Kubička D, Garay A L, Mäki-Arvela P, Heikkilä T, Salmi T, Murzin D Y. Top Catal, 2009, 52: 380

14 Vuori H, Silvennoinen R J, Lindblad M, Österholm H, Krause A O I. Catal Lett, 2009, 131: 7

15 Mouli K C, Sundaramurthy V, Dalai A K. J Mol Catal A, 2009, 304: 77
16 McVicker G B, Daage M, Touvelle M S, Hudson C W, Klein D P, Baird Jr W R, Cook B R, Chen J G, Hantzer S, Vaughan D E W, Ellis E S, Feeley O C. J Catal, 2002, 210: 137

17 Rabl S, Haas A, Santi D, Flego C, Ferrari M, Calemma V, Weitkamp J. Appl Catal A, 2011, 400: 131

18 Weitkamp J, Rabl S, Haas A, Santi D, Ferrari M, Calemma V. In: Ernst S, Lercher A, Lichtscheidl J, Marchionna M, Nees F, Santacesaria E ed. Preprints of the Conference - The Future Role of Hydrogen in Petrochemistry and Energy Supply, DGMK Tagungsbericht 2010-3. Hamburg: DGMK, 2010. 77

19 Weitkamp J, Rabl S, Haas A, Santi D, Ferrari M, Calemma V. Oil Gas Eur Mag, 2011, 37: 94

20 Rabl S, Santi D, Haas A, Ferrari M, Calemma V, Bellussi G, Weitkamp J. Microporous Mesoporous Mater, 2011, 146: 190

21 Ipatieff V N, Pines H, Meisinger E E. J Am Chem Soc, 1949, 71: 2685

22 Pentschev V, Davidova N. Brennst-Chem, 1968, 49: 33

23 Daage M, McVicker G B, Touvelle M S, Hudson C W, Klein D P, Cook B R, Chen J G, Hantzer S, Vaughan D E W, Ellis E S. Stud Surf Sci Catal, 2001, 135: 159

24 Davidova N, Penčev V, Beránek L. Collect Czech Chem Commun, 1968, 33: 1229

25 Nylén U, Delgado J F, Järås S, Boutonnet M. Appl Catal A, 2004, 262: 189

26 Rao P R H P, Leon y Leon C A, Ueyama K, Matsukata M. Microporous Mesoporous Mater, 1998, 21: 305

27 Miyamoto Y, Katada N, Niwa M. Microporous Mesoporous Mater, 2000, 40: 271

28 Miller J T, Schreier M, Kropf A J, Regalbuto J R. J Catal, 2004, 225: 203

29 Anderson J A, Férnandez-García M, Martínez-Arias A. In: Anderson J A, Férnandez-García M ed. Supported Metals in Catalysis, Catalytic Science Series, Vol. 5. London: Imperial College Press, 2005. 139

30 McVicker G B, Baker R T, Garten R L, Kugler E L. J Catal, 1980, 65: 207

31 Marins de Oliveira A, Costilla I, Gigola C, Baibich I M, Teixeira da Silva V T, Castella Pergher S B. Catal Lett, 2010, 136: 185

32 Frye C F, Weitkamp A W. J Chem Eng Data, 1969, 14: 372

33 Allinger N L, Coke J L. J Am Chem Soc, 1960, 82: 2553

34 Weitkamp A W. Adv Catal, 1968, 18: 1

35 Lai W C, Song C. Catal Today, 1996, 31: 171

36 Foger K, Anderson J R. J Catal, 1979, 59: 325

37 Carter J L, Cusumano J A, Sinfelt J H. J Catal, 1971, 20: 223

38 Maire G, Plouidy G, Prudhomme J C, Gault F G. J Catal, 1965, 4: 556

39 Anderson J R, Avery N R. J Catal, 1966, 5: 446

40 Weitkamp J, Farag H. In: Beyer H K, Fejes P, Jacobs P A, Tempere J F ed. Proceedings of the Symposium on Zeolites. Szeged, Hungary, 1978. 327

41 Turova-Polyak M B, Sosnina I S, Belikova N A, Plate A F. Zh Org Khim, 1966, 2: 2162

42 Kozina M P, Mirzaeva A K, Sosnina I E, Elagina N V, Skuratov S M. Dokl Akad Nauk SSSR, 1964, 155: 1123 
43 Egan C J, Langlois G E, White R J. J Am Chem Soc, 1962, 84: 1204

44 Ernst S, Weitkamp J. Proceedings of the International Symposium on Zeolite Catalysis. Siófok, Hungary, 1985. 457

45 Weitkamp J. ACS Symp Ser, 1975, 20: 1

46 Martens J A, Jacobs P A, Weitkamp J. Appl Catal, 1986, 20:
239

47 Nylén U, Arechederra J M, Pawelec B, Delgado J F, Pascual M P, Fierro J L G. Energy Fuels, 2008, 22: 2138

48 Engler E M, Andose J D, von R Schleyer P. J Am Chem Soc, 1973, 95: 8005

49 Gault F G. Adv Catal, 1981, 30: 1 